\title{
Analysis and Simulation Application for Manual Work Performance Improvement
}

\author{
W. K. Hwam, Y. Chung, D. S. Chang, and S. C. Park
}

\begin{abstract}
Presented in this paper is a framework for analysis and simulation application for performance improvement of manual work in a manned assembly line. In a manufacturing system, productivity is a key of competitiveness for output products, and the manual work performance is one of the decisive factors of productivity of a manned assembly line. However, existing approaches to the manufacturing systems are limited to matters of the plant layout or the robot tasks design in the automated factory and to the manual work are concentrated on the ergonomic based workload analysis. Consequently, the modern approach for the manual work performance improvement has not been researched. As a solution of the current problem, this study proposes an application that analyzes manual work based on work design approach using video-recording, and the system executes a brief simulation of newly derived work standard from the analysis.
\end{abstract}

Index Terms-Assembly line, manual work, simulation, work video analysis.

\section{INTRODUCTION}

Productivity of a manufacturing system is one of the important elements that decide the enterprise competitive power, such as market flexibility and quality management. Manufacturing enterprises must carry out an activity for productivity improvement continuously. The manned assembly line is a process of manufacturing systems, which is suitable to massive manufacture having better flexibility than the automated system. This process has been adopted in the industry for electronic appliances, i.e. television and refrigerator. Because the industry has many different product types and frequent changes, to design the manufacturing system as fully automated using dedicated tools is hindered by the view of cost-effectiveness. The process is structured by three factors of machine, worker and material (see Fig. 1), and the productivity is determined by machine capacity, worker performance and product design. After built up all the equipment and operation plans of assembly lines, it is difficult to modify the layout or replace the equipment. Therefore, improvement of the worker performance is an appropriate approach to the productivity enhancement of installed lines. Although jobs on an assembly line normally does not require high-skilled workers because of an aggregation of repetitive tasks, such as picking a component from toolset and assembling a component with a base laid on a conveyor, a slow workstation by a low-skilled worker

Manuscript received May 10, 2013; revised July 10, 2013.

The authors are with the Dept. of Industrial Engineering, Ajou University, Korea (e-mail: lunacy@ajou.ac.kr, webmacom@ajou.ac.kr, scpark@ajou.ac.kr, yongho1230@gmail.com). causes delay of former workstations and idle of latter workstations. In other words, poor performance of one workstation affects to the entire assembly line flow, and it causes, as a result, a decline of productivity of the line.

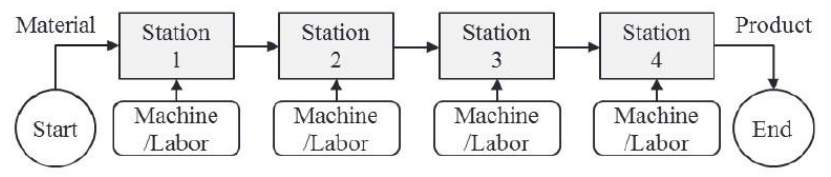

Fig. 1. Manned assembly line process.

Existing research and tools for the productivity improvement of manufacturing systems can be classified as manufacturing process design and work method design. Manufacturing process design is research to design and manage a system regarding with equipment installation layout, capacity planning, operation process management and operation and resource scheduling. This research is to select process type (i.e. job shop, batch, assembly, continuous) based on the diversity, flexibility and yield of output products of the system and to apply the selected process to the target manufacturing system. Construction of a manufacturing system requires a lot of resources, and it also needs almost equal resources to modify the constructed system. Thus, this research has to be considered seriously before implementation of a system. Former research on this matter is following: Askin and Mitwasi proposed a mathematical heuristic model for facility layout, process selection and capacity planning of a manufacturing system based on the previous approaches [1], such as linear programming [2], heuristic rule based process planning [3], the Lagrangian relaxation techniques for hierarchical production planning [4], quadratic assignment problem (QAP) and graph theory for facilities layout [5]-[7], procedures for assigning operations to machines [8], [9]. Bazargan-Lari reported layout designs in cellular manufacturing for a dynamic food manufacturing and packaging system [10], and Deb and Bhattacharyya adopted fuzzy theory to plan manufacturing facilities layout [11]. Reifur suggested a proper automation degree in assembly lines [12], and Park and Chang proposed a virtual-factory based simulation for verification of productivity and agile stabilization of a production system [13].

Work method design is to research for the effective capacity maximization of a system and it is a key factor to improve productivity of a system after implementation of the system. The research has been applied to the automated system and manned systems. For the automated manufacturing system, much of research was progressed about robot OLP (Off-Line Programming) for machine work process planning, such as cutting, welding and casting 
[14]-[16]. For manual work in the manned manufacturing system, there are two streams of research: traditional work design and Ergonomics. The traditional work design is a methodology that is based on manual work analysis to remove inefficiency from worker's movements or working process. This methodology analyzes work using various charts for macro motion study; such as flow process chart and operation process chart [17], [18]; and micro motion study; such as man-machine chart, operation analysis chart and SIMO chart (an abbreviation for simultaneous motion cycle chart) [19]. The macro motion study is a research method that breaks a job down into tasks and movements and the micro motion study is a method that defines a unit movement as several body motions. Therefore, work design is able to identify inefficient elements of the wide range from a body action to tasks by using charts to describe work. Ergonomics is another methodology to analyze manual work, but it concentrates on the human factors, which are worker's motions, therblig and postures, to measure the workload and identifies overloaded body parts of the worker to maintain well-performance by retaining health and safety of the worker. In order to analyze manual work based on ergonomics, it has been used three methods; video-recording, marker and questionnaire. The video-recording method requires a video that captured the entire work of the workers, and it analyzes the video itself or results of the simulation-based virtual experiment that utilizes a virtual work model converted from the video. The marker based method attaches markers onto the body of the worker to track the motion or measure the change of electromyogram or electrocardiogram. The marker based analysis result exactly indicates problematic motions or postures. The questionnaire method is a worker completes a questionnaire regarding the experience gained during the work. This method predicts workloads of the worker by an analysis result of the questionnaire.

Despite much former research for productivity improvement of manufacturing system, the research for worker performance improvement is still stayed in the traditional approaches that are focuses on partial efficiency issues of manual work which can be described by single chart Although many latest technologies are adopted in ergonomic approach, it demands too much of the costs, efforts and time to apply with the whole assembly line. In the research for the line balancing problem of the assembly line process, labor productivity for line productivity improvement was mentioned, but the research spotlighted the stabilization of cycle-time balance of work stations using cycle-times assumed as constant values. Thus, from the current research situation for the manual work itself, there is no solution for improvement of overall manual work performance to meet recent IT based technology trends. In the manned assembly line, manual work analysis for worker performance improvement should be the first activity to improve the line productivity, but the lack of the related research causes impediment for applying the research for the next activities of productivity improvement into the real system. This study proposes a framework to solve the lack in manual work analysis system. The implemented system based the proposed framework was applied for worker performance improvement in manned assembly lines of a global electronic manufacturer.

The overall structure of this paper is as follows. Section II gives description of the approach of this study, and the implemented system based on the approach is represented in Section III. Finally, the summary and future study of this paper is addressed in Section IV.

\section{APPRAOCH}

Manual work of a manned assembly line is a repetitive work by a worker. Therefore, this paper defines the manual work as next. Manual work is made by an aggregation of cycles. A cycle that means a single operation contains several tasks, and a task is composed of worker's motions. Fig. 2 depicts this decomposition of manual work to explain the structure of manual work, and an example of a task is shown in Fig. 3. In the example, a task of the worker can be described as 'tighten a screw using a power screwdriver'. The task also can be described as three motions; 'grab a power screwdriver', 'move a power screwdriver' and 'tighten a screw'.

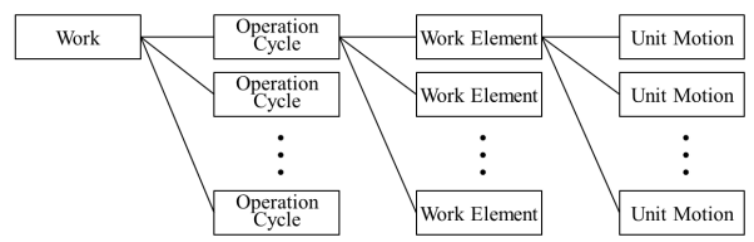

Fig. 2. Decomposition of manual work

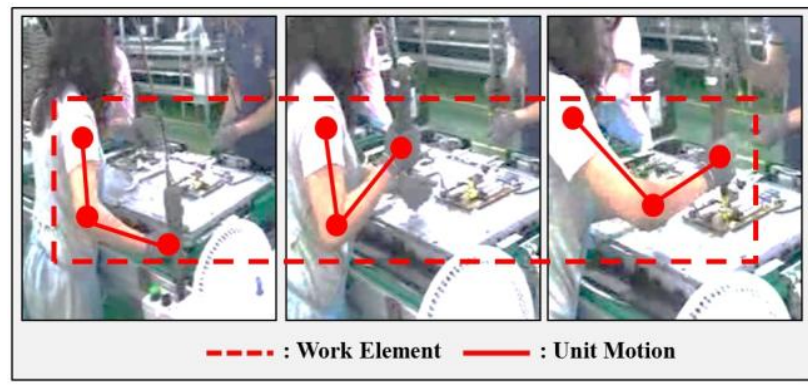

Fig. 3. Example of element action and unit motions.

In the traditional work design, the macro motion study is appropriate for analysis of work elements and operation cycles and the micro motion study aims to analyze unit motions of a worker. For the improvement of manual work performance, it is needed a method of work analysis based on the view that integrates both of the macro and micro motion study. But existing research approaches independently and separately to the macro and micro motion study. Thus, this study designs a chart template for the integration of different levels of the structure of work decomposition. The designed template in this paper describes a work element with element name and type and a unit motion as motion name and type, waste type, start time and time interval. By the designed template, an element is represented by several unit motions and a single operation is explained by several work elements. Fig. 4 shows a structure and details of the designed template.

This study proposes a framework for construction of a system to analyze manual work recorded in video based on the template and to simulate the analysis result. The system 
based on the proposed framework imports a video file that records manual work, and it analyzes the imported video using a chart which is based on the designed template. In the analysis mode of the system, a user specifies sections of an imported video as unit motion, work element and operation cycle of work elements and classifies the value adding type of motions. Sections of the video can be excluded from work video playback for the simulation of a modified manual work standard devised from the analysis. In addition, the system is able to obtain a standard time of a single operation cycle, and it changes the belonged workstation of an element action to optimize the line balancing ratio of an assembly line by comparing with the standard time of other workstations.

\begin{tabular}{|c|c|c|}
\hline Work Element & \multirow{3}{*}{$\begin{array}{l}\text { Work Element Types } \\
\cdot \bullet: \text { : Operation } \\
\cdot \Rightarrow \text { :Transportation } \\
\cdot \diamond \text { : Inspection }\end{array}$} & \multirow{2}{*}{$\begin{array}{l}\cdot \nabla: \text { Storage } \\
\cdot \mathrm{D} \text { : Delay }\end{array}$} \\
\hline $\begin{array}{l}\text { Element Name } \\
\text { Element Type }\end{array}$ & & \\
\hline $1 . .1$ & & \\
\hline 1..N & \multirow{3}{*}{$\begin{array}{l}\text { Value Adding Types } \\
\text { - Value Adding } \\
\text { - Base Value Adding } \\
\text { - None Value Adding }\end{array}$} & \multirow{3}{*}{$\begin{array}{l}\text { Waste Types } \\
\text { - Stockpile } \\
\text { - Overproduction } \\
\text { - Standing } \\
\text { - Transporting } \\
\text { - Poor Condition } \\
\text { - Action } \\
\text { - Processing }\end{array}$} \\
\hline Unit Motion & & \\
\hline $\begin{array}{c}\text { Motion Name } \\
\text { Value Adding Type } \\
\text { Waste Type } \\
\text { Start Time } \\
\text { Time Interval }\end{array}$ & & \\
\hline
\end{tabular}

Fig. 4. Designed template structure and detail.

\section{FRAMEWORK AND IMPLEMENTATION}

The system proposed in this study is a software tool to help users to analyze a video which was recording manual work of workers and to derive improvements based on the analysis of existing work. The system requires a work video as a resource, and it plays a video file on a screen. A user defines sections of the video, and each section is input an analysis from a user. The system provides a chart for allowing a user to input analysis data and stores the data in the database. The analysis result is displayed using graphs, such as a Gantt chart and bar chart, to represent the current state of a work process. A user is able to revise the existing work process based on the analysis result, and the revised work process allows to be simulated in the system by exclusion of deleted elements from the analysis result. The revised work process is exported as a new standard work process of the field and as a work station performance for line balancing of a line. This framework of the proposed system is depicted in Fig. 5.

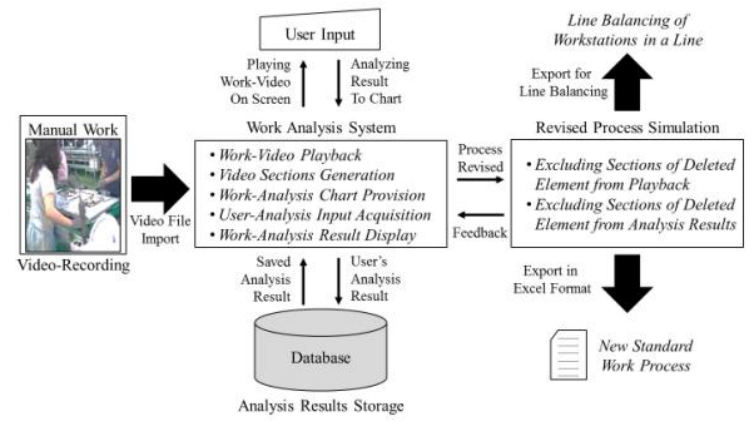

Fig. 5. Framework of proposed system.

According to the framework, the system requires to have functions of video-playback, user-writeable work analysis chart, graph display of results and excepting user-selected work from analysis. Fig. 6 represents the layout of the implemented system, and each part of the layout is a function for video-playback (A), work analysis chart (B) and result display using graph (C). The work analysis chart of the system is structured based on the designed template in section 2 . The work analysis chart in the system has columns to insert information of work elements (D), information of unit motions (E), motion duration (F) and motion exclusion $(\mathrm{G})$. The work that is analyzed by this system is repetitive, thus, a user can insert separators to distinguish cycle start and end on the chart. In conclusion, the system is able to cover the range of work analysis that is between the motion and the operation.

As a result of the system, a working time of the workstation is obtained from a standard cycle time of the analyzed work. A manned assembly line is structured by several workstations, and the minimum process time of the line is calculated by the sum of a cycle time of workstations. However, a real process time of the line is larger than the sum, because there are many chances to occur idle on workstations by various reasons. The most possible cause of idle states is from unbalanced cycle times of workstations, therefore, the line balancing of a line is required. The line productivity is able to be simulated by the discrete simulation system using the revised cycle times of workstations (see Fig. 7).

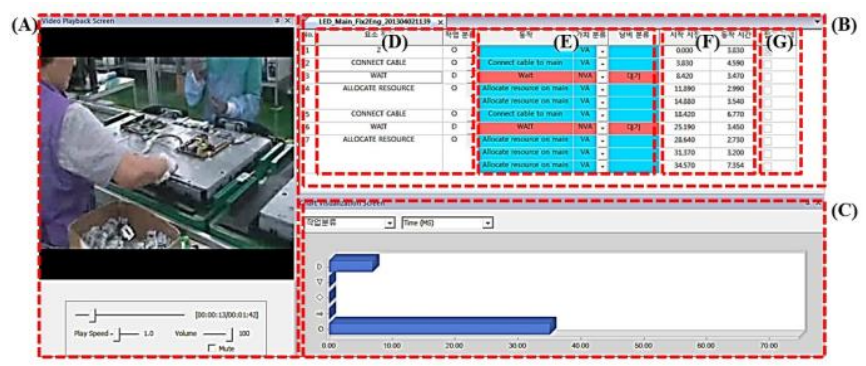

Fig. 6. Implemented system.

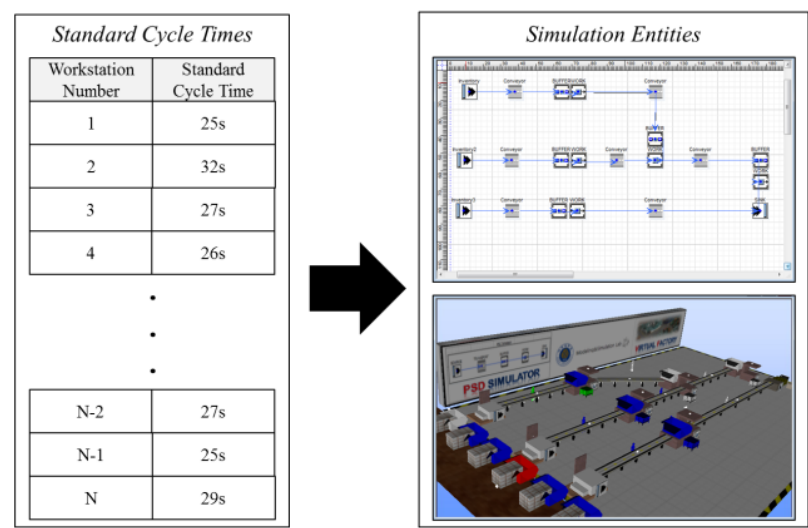

Fig. 7. Line balancing simulation by discrete simulation system.

\section{SUMmARY AND FUtURE STUdY}

This paper is research for the manual work improvement of a workstation in a manned assembly line. For the improvement, this paper proposes the work measurement method using a chart that is designed in Section II. Manual work is able to be analyzed on the view of both macro and micro motion study by the designed chart. The system proposed in this paper is developed to help a user to analyze manual work using video playback. A user of the system is 
able to analyze work videos and write the analysis result onto the designed chart. The analysis result can be modified and simulated in the system for improvement of the work process.

In the future study, the system is improved for better analysis of work process by several functions such analysis functions based on time flowing, comparison of analyses, collaboration work of several workers and line balancing of workstations. Thus, workstations of a manned assembly line are analyzed in the range from the human motions of a worker of a workstation and to the entire line.

\section{ACKNOWLEDGMENT}

This work (Grants No. C00035790100384919) was supported by Business for Cooperative R\&D between Industry, Academy, and Research Institute funded Korea Small and Medium Business Administration in 2013. This work is also supported by the Defense Acquisition Program Administration (DAPA), the Agency for Defense Development (ADD) under the Contract No. UD110006MD (DAPA), UD100009DD and UD120035JD (ADD). The authors wish to express sincere gratitude for the financial support.

\section{REFERENCES}

[1] R. G. Askin and M. G. Mitwasi, "Integrating facility layout with process selection and capacity planning," European Journal of Operation Research, vol. 57, pp. 162-173, 1992.

[2] L. A. Johnson and D. C. Montgomery, Operations Research for Production Planning, Scheduling, and Inventory Control, New York: John Wiley. 1974.

[3] T.-C. Chang and R. A. Wysk, An Introduction to Automated Process Planning Systems, New Jersey: Prentice-Hall. 1985.

[4] S. C. Graves, "Using Lagrangean techniques to solve hierarchical production planning problems," Management Science, vol. 28, no. 3 , pp. 260-275. 1982.

[5] F. S. Hillier and M. M. Connors, "Quadratic assignment problem algorithms and the location of indivisible activities," Management Science, vol. 13, no. 1, pp. 42-57. 1966.

[6] B. Golany and M. J. Rosenblatt, "A heuristic algorithm for the quadratic assignment formulation to the plant layout problem," International Journal of Production Research, vol. 27, no. 2, pp. 293-308. 1989.

[7] L. R. Foulds, P. B. Gibbons, and J. W. Giffin, "Facilities layout adjacency determination: An experimental comparison three graph theoretic heuristics," Operations Research, vol. 33, no. 5, pp. 1091-1106, 1985.

[8] H. Co and A. Araar, "Configuring cellular manufacturing systems," International Journal of Production Research, vol. 26, no. 9, pp. 1511-1522, 1988.

[9] R. G. Askin and S. Chiu, "A graph partitioning procedure for machine assignment and cell formation in group technology," International Journal of Production Research, vol. 28, no. 8, pp. 1555-1572, 1990.

[10] M. B. Lari, "Case study: Layout designs in cellular manufacturing," European Journal of Operation Research, vol. 112, pp. 258-272, 1999.

[11] S. K. Deb and B. Bhattacharyya, "Fuzzy decision support system for manufacturing facilities layout planning," Decision Support System, vol. 40, pp. 305-314. 2005.
[12] B. Reifur, "Optimum assembly automation level selection module as the component of advisory system," Archives of Civil and Mechanical Engineering, vol. 7, no. 1, pp. 75-83, 2007.

[13] S. C. Park and M. Chang, "Hardware-In-The-Loop Simulation for a Production System," International Journal of Production Research, vol. 50, no. 8, pp. 2321-2330, 2012.

[14] S. C. Park and B. K. Choi, "Boundary extraction algorithm for cutting area detection," Computer-Aided Design, vol. 33, pp. 571-579, 2001.

[15] S. C. Park and Y. C. Chung, "Tool-Path generation from measured data," Computer-Aided Design, vol. 35, pp. 467-475. 2003.

[16] J. Ruan, K. Eiamsa-ard, and F. W. Liou, "Automatic process planning and toolpath generation of multiaxis hybrid manufacturing system," Journal of Manufacturing Processes, vol. 7, no. 1, pp. 57-68, 2005.

[17] F. B. Gilbreth, Motion Study: A Method for Increasing the Efficiency of the Workman, New York: Van Nostrand, 1911.

[18] F. B. Gilbreth and L. M. Gilbreth, Process Charts, New York: The American Society of Mechanical Engineers, 1921.

[19] A. Freivalds and B. W. Niebel, Niebel's Methods, Standards, and Work Design: Twelfth Edition, New York: McGraw-Hill, 2009.

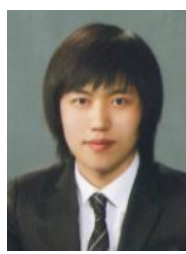

Won K. Hwam received a bachelor degree (2011) in industrial and information system engineering and a master degree (2013) in industrial engineering, Ajou University, Korea. He is now a $\mathrm{Ph}$. D candidate in industrial engineering, Ajou University, Korea, and he is a member of modeling and simulation laboratory, which is an affiliation of department of industrial engineering, Ajou University. He is interested in distributed simulation system, synthetic environment, and manufacturing simulation system.

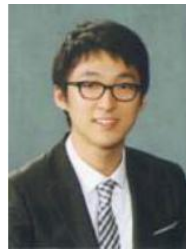

Yongho Chung received a bachelor degree (2011) in industrial and information system engineering and a master degree (2013) in industrial engineering, Ajou University, Korea. $\mathrm{He}$ is now a $\mathrm{Ph}$. D candidate in industrial engineering, Ajou University, Korea, and he is a member of modeling and simulation laboratory, which is an affiliation of department of industrial engineering, Ajou University. He is interested in kinetic modeling, and mesh generation.

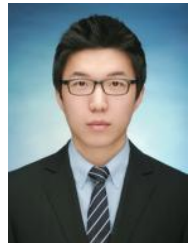

Dae S. Chang received a bachelor degree (2012) in industrial and information system engineering, Ajou University, Korea. He is now a student for a master's degree in industrial engineering, Ajou University, Korea, and he is a member of modeling and simulation laboratory, which is an affiliation of department of industrial engineering, Ajou University. He is interested in distributed simulation system, Digital Manufacturing System, and CAD/CAM/CAPP.

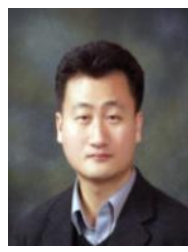

Sang C. Park was granted his bachelor (1994), master (1996) and Ph.D. (2000) degrees in industrial engineering, Korea Advanced Institute of Science and Technology (KAIST). After his doctor's course, he had been a senior researcher of Cubictek, Korea, for 2 years from 2000. In 2002, he moved into DaimlerChrysler and took a srole of research specialist, ITM Dept, for 3 years. Currently, he is an associate professor in Dept. of industrial and information systems engineering, Ajou University, Korea, since 2004. He is interested in modeling and simulation (M\&S), combat simulation for defense, digital manufacturing system, computer graphics and computational geometry and sculptured surface modeling and $\mathrm{NC}$ machining. 